\title{
Febrile Seizures in Epileptic Chicks: The effects of Phenobarbital, Phenytoin and Valproate
}

\author{
D.D. Johnson, K.D.A. Crawford and R.D. Crawford
}

\begin{abstract}
SUMMARY: Epileptic seizures can be evoked in chicks homozygous for the epileptic seizure gene (epi, epi) by elevating their body temperature using microwave diathermy. These seizures precede and differ in motor seizure pattern from a second clonic-tonic seizure produced by hyperthermia in both epileptic and carrier (heterozygote, Epi, epi) chicks. Hyperthermia did not evoke seizures in adult epileptic chickens. Phenobarbital delayed the onset of epileptiform seizures whereas phenytoin and valproate had no effect. These data suggest that epileptic chicks may provide a suitable model for studies on febrile convulsions.
\end{abstract}

RÉSUMÉ: Chez des poulets homozygotes pour le gêne épileptique (epi, epi) il est possible de provoquer des crises épileptiques en élevant la température corporelle à l'aide de diathermie aux ondes courtes. Ces crises précèdent et diffèrent du patron de crises motrices suivant la crise tonicoclonique produite par l'hyperthermie chez le poulet épileptique ou porteur (hétérozygote; Epi, epi). L'hyperthermie ne provoque pas de crises chez les poulets épileptiques adultes. Le début de ces crises épileptiques est retardé par le Phenobarbital, alors que le phenytoin et le Valproate n'ont aucun effet. Ces résultats indiquent que les poulets épileptiques pourraient servir de modèle pour l'étude des convulsions fébriles.

Can. J. Neurol. Sci. 1983; 10:96-99

The incidence of febrile seizures in the general population is reported to be between 2-5 per 100 children (Van den Berg and Yerushalmy, 1969; Ross, 1973; Tsuboi, 1977). Several studies have suggested a genetic determinant for susceptibility to febrile convulsions (Ounsted, 1971; Lennox-Buchthal, 1971). In humans, as well as experimental animals (Millichap, 1959), the susceptibility to febrile seizures is an age dependent transient phenomenon, presumably as a result of brain immaturity. Therapeutic trials in humans have indicated that phenobarbital (Faero et al., 1972) and valproic acid (Cavazzuti, 1975) but not phenytoin (Melchior et al., 1971) can be used effectively in the prophylaxis against febrile seizures.

Although febrile convulsions have been studied in normal experimental laboratory animals (Millichap, 1965; Julien and Fowler, 1977; Kasting et al., 1981) existing genetic models of epilepsy in animals do not appear to have been evaluated as potential experimental models of febrile seizures for either pharmacological studies or for investigating mechanisms by which hyperthemia precipitates convulsions. The high seizure susceptibility in epileptic fowl is the result of an autosomal recessive mutation (Crawford, 1970). Spontaneous seizures are evident at hatching and continue to occur throughout the bird's life span. Seizures can be evoked in homozygotes (epileptics) by stroboscopic stimulation whereas heterozygotes are unaffected (Crichlow and Crawford, 1974). Epileptic chickens also have grossly abnormal inter-ictal EEG activity (Crichlow and Crawford, 1974). Seizures elicited in epileptics by stroboscopic stimulation can be abolished or reduced in severity by phenobarbital, phenytoin, valproic acid, trimethadione and the benzodiazepines but are unaffected by ethosuximide (Johnson et al., 1979).

The value of any model of human pathology is dependent on how closely the syndrome in the model parallels that in humans. Thus, an appropriate model of febrile seizures should have a high seizure susceptibility in response to hyperthermia, susceptibility should be age dependent, and it should be sensitive to those anticonvulsant agents known to be effective in preventing febrile seizures in humans. In order to evaluate epileptic fowl as an experimental model of febrile convulsions, experiments were conducted to determine if epileptic chicks had a higher seizure susceptibility in response to hyperthermia than their non-epileptic heterozygote hatchmates and whether the susceptibility to febrile seizures was age dependent. Since febrile seizures in children can be prevented by prophylactic treatment with phenobarbital or valproic acid but not by phenytoin the effect of these drugs on seizures evoked by hyperthermia in chicks was also determined.

\section{METHODS}

The 2-5 day old chicks and adult chickens used in this study were derived from the epilepsy mutant population maintained in our laboratories by mating homozygous recessive affected birds (epi epi) with heterozygous normal birds (Epi epi). The phenotype of the offspring was determined by exposure to intermittent photic stimulation (IPS). Homozygotes (epileptics) convulse in response to IPS

From the Department of Pharmacology, College of Medicine and the Department of Animal and Poultry Science, College of Agriculture,

University of Saskatchewan, Saskatoon.

Received Sept. 15, 1982. Accepted for publication January 17, 1983.

Reprint requests to: Dr. D.D. Johnson, Dept. of Pharmacology, College of Medicine, University of Saskatchewan, Saskatoon,

Saskatchewan, Canada S7N OWO. 
whereas heterozygotes (carriers) are unaffected (Crichlow and Crawford, 1974).

Hyperthermia was induced in 2-5 day-old chicks by means of a microwave diathermy generator (The Microtherm (R), Model MW-1, The Burdick Corporation, Milton, Wisconsin) according to methods described previously (Millichap, 1965). The dose of radio-frequency energy was maintained at $80 \%$ of the maximal output of the generator (Julien and Fowler, 1977). The director was maintained at a constant distance from the chick which was confined in a glass cylinder with a diameter of 4 inches. Body temperature was not measured in these studies. It has previously been reported that, for any given energy setting on the diathermy apparatus, the threshold convulsive temperature was independent of the intensity and duration of the heating stimulus (Millichap, 1965). The experiments were performed by placing each chick in the glass cylinder, starting the diathermy apparatus and recording the time to onset (latency) of the seizure. In the initial experiments the time to onset of seizures was compared in epileptic $(n=14)$ and carrier $(n=12)$ chicks.

In studies where drugs were administered, only epileptic chicks were used. All drugs were administered intraperitoneally. Phenobarbital and valproate were dissolved in distilled water. Phenytoin was dissolved in propylene glycol (40\%), alcohol (10\%) and water for injection (50\%). In all cases chicks in the control groups received an equivalent volume, on a weight basis, of the solvent. The doses and time intervals were selected on the basis of previous studies on the ability of these drugs to prevent seizures in response to IPS (Johnson et al., 1979). Six chicks were used in each of the control and treated groups in experiments with phenobarbital. All other control and treated groups contained 10 chicks.

Five adult chickens were placed in a bell jar with the diathermy generator placed 3 inches from the head of the chicken. The dose of radiofrequency energy was maintained at $80 \%$ of maximal output.

The statistical significance of differences in the means (i.e., time to seizure) was determined by Student's $t$-test.

\section{RESULTS}

When epileptic chicks were exposed to microwave diathermy to produce hyperthermia two types of motor seizure patterns were observed. The first type resembled that elicited in epileptic fowl by stroboscopic stimulation (Crichlow and Crawford, 1974). It consisted of upward and backward extension of the head and neck followed by violent uncoordinated movements of the wings and legs. Epileptic chicks recovered from this seizure even though the diathermy was continued. In some chicks this pattern was repeated up to three times. In all epileptic chicks a second seizure type was observed when the diathermy was continued. The motor pattern observed in this type was identical to that produced by hyperthermia in carrier chicks. The onset was preceded by a brief quiescent period followed by symmetrical clonic movements of the legs and wings at which time the chick flipped on to its back. The brief period of clonus ( $<30$ seconds) was followed by rigid tonic extension of the legs. Figure 1 illustrates the time required to elicit these seizure types (i.e. latency) in 2-day-old carrier and

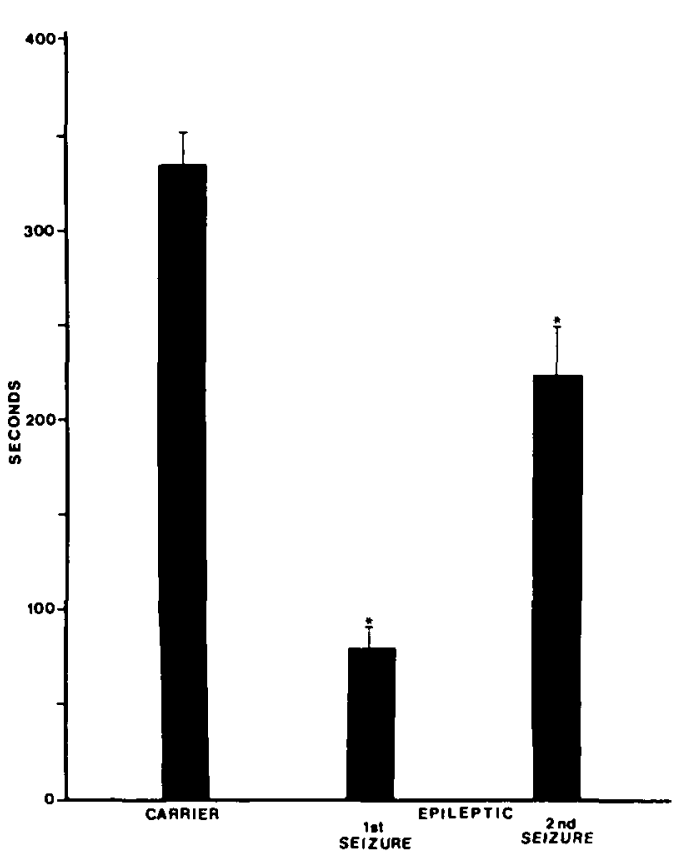

Figure 1 - Seizure latency in three-day-old carrier (heterozygotes) and epileptic (homozygotes) chicks exposed to microwave diathermy illustrating the high seizure susceptibility of epileptics when subjected to hyperthermia. Hyperthermia in epileptics evoked an epileptiform seizure (1 st seizure) and subsequently a clonic-tonic seizure (2nd seizure). The latency was significantly shorter $(P<0.05)$ for both seizure types when compared to carriers $(n=12$ for carriers, 14 for epileptics).

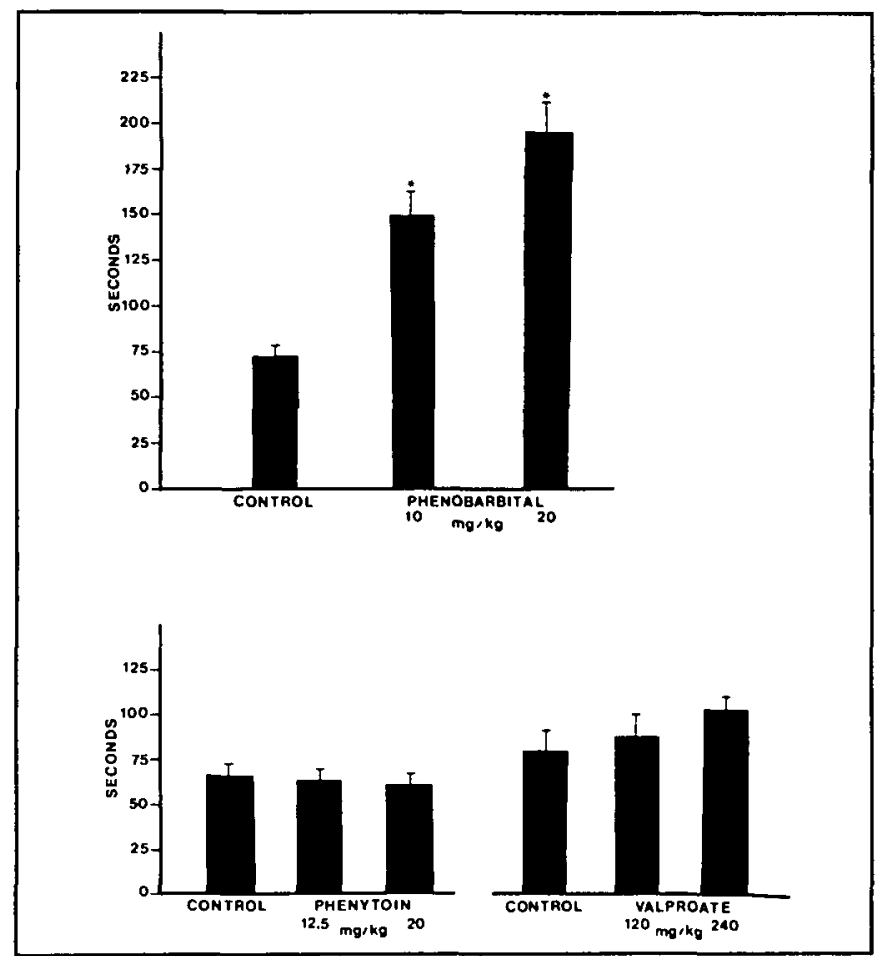

Figure 2 - The effects of phenobarbital, phenytoin and valproate on the time to onset of epileptiform seizures in two-day-old epileptic chicks. Phenobarbital $(P<0.05)$, but not phenytoin or valproate, produced a significant increase in the latency of epileptiform seizures when compared to non-treated epileptic chicks (controls). ( $n=6$, group in phenobarbital experiments, $n=10$, group in phenytoin and valproate experiments). 
epileptic chicks at $80 \%$ of the maximum output from the diathermy apparatus. Using this procedure, the first seizure occurred in epileptics at $83 \pm 11(\mathrm{SE})$ seconds $(n=14)$. The mean times of onset of the second seizure type were $238 \pm 26$ seconds $(n=14)$ in epileptics and $337 \pm 18$ seconds in carriers $(n=12)$. The difference in time of onset between epileptics and carriers for the second seizure type was statistically significant $(\mathrm{P}<0.001)$ indicating a higher seizure susceptibility for the latter type of seizure in the epileptics.

The effects of phenobarbital, phenytoin and valproate on the time of onset of seizures in epileptic chicks are shown in Fig. 2. In two-day-old epileptics exposed to diathermy, phenobarbital at doses of 10 and $20 \mathrm{mg} / \mathrm{kg}$ (i.p.) produced a significant delay in the onset of seizures (first seizure type) $(n=6)$. Phenytoin $(12.5$ and $20 \mathrm{mg} / \mathrm{kg}$ i.p.) had no significant effect on the time of onset of seizures (Fig. 2) $(n=10)$. It was not possible to increase the dose of phenytoin because of obvious neurotoxicity at higher doses. As has been reported for phenytoin in adult epileptic chickens (Davis et al., 1978), phenytoin in doses of $30 \mathrm{mg} / \mathrm{kg}$ produced early stages of the motor seizure pattern in many chicks and typical epileptiform seizures in others suggesting that high phenytoin concentrations activate the seizure process. Although valproic acid (120 and $240 \mathrm{mg} / \mathrm{kg}$ ) appeared to produce some increase in the time to onset of epileptiform seizure activity (Fig. 2) the increase was not statistically significant.

Exposure of five adult epileptic chickens to microwave diathermy did not result in seizure activity even though the diathermy was continued until the birds became moribund due to the hyperthermia.

\section{DISCUSSION}

The results presented here indicate that hyperthermia will activate the seizure process in chicks with an inherited high seizure susceptibility due to an autosomal recessive mutation. The initial seizure pattern evoked by microwave diathermy resembled the spontaneous seizures occurring in these chicks (Crawford, 1970) and those evoked by stroboscopic stimulation (Crichlow and Crawford, 1974). The second seizure type evoked by diathermy, consisting of rapid symmetrical clonus of the wings and legs and terminating in rigid extension of the legs was identical in epileptic and carrier chicks and was similar to that reported in rodents subjected to the same procedure (Millichap, 1959). However, it is noteworthy that the time to onset of the latter seizure type was significantly shorter in the epileptic chicks. Both observations are consistent with the high seizure susceptibility in this mutant. The precipitation of these seizures by hyperthermia in young chicks but not in adult chickens is consistent with this fact that febrile seizures in humans are only observed in young children.

The mode of activation of the epileptic process in febrile illness in children is not known. It has been suggested that fever alone may be capable of precipitating seizures in the normal immature nervous system, that hyperthermia may activate an epileptogenic focus which is otherwise quiescent, or that fever may precipitate convulsions in a child with a hereditary predisposition (Schmidt et al., 1956). The present data and previous reports suggest that all of the above pos- sibilities may apply in the immature brain but not in the mature brain since hyperthermia did not precipitate seizures in adult epileptic chickens. Seizures can be produced by hyperthermia in young normal rodents and cats but seizure susceptibility decreases with increasing age (Millichap, 1959). In adult monkeys with experimental epileptogenic foci produced by injection of alumina gel into the sensory motor cortex seizures could not be precipitated by hyperthermia (Schmidt et al., 1956). The higher seizure susceptibility in response to hyperthermia in young chicks and rodents is possibly due to delayed development of inhibitory pathways in the brain. From the present data it cannot be precisely determined whether hyperthermia activates a specific focus of epileptogenic activity in the epileptic chick brains or if the seizure activity is generalized from the onset. However, the similar motor pattern exhibited in both the initial febrile seizures and that observed when the chicks are exposed to stroboscopic stimulation (Crichlow and Crawford, 1974) suggest that the same seizure inducing mechanism is activated. The differences in the motor seizure pattern between the initial epileptiform seizure and the terminal clonic-tonic seizures also suggest that the former are epileptic seizures precipitated by hyperthermia. The observation that the terminal clonic-tonic seizure occurred earlier in the epileptics suggests that seizures may occur at lower body temperature in cases where there is a hereditary predisposition to convulse.

In children with histories of repeated febrile convulsions long-term prophylaxis can be achieved with daily phenobarbital administration (Faero et al., 1972). An appropriate animal model of the syndrome in children should therefore be sensitive to the anticonvulsant effect of phenobarbital. In the present study phenobarbital, in doses of 15 and 20 $\mathrm{mg} / \mathrm{kg}$, delayed the onset of epileptiform seizures evoked in epileptic chicks by microwave diathermy. These doses of phenobarbital did not produce overt signs of sedation and had no apparent effect on spontaneous motor activity. The doses selected were those that provide protection against induction of seizures in adult epileptic fowl by photic stimulation (Johnson et al., 1977). In adults these doses were also without toxic effects.

In previous studies identical methodology has been used to study the effects of phenobarbital, phenytoin and valproic acid on febrile seizures in mice (Millichap, 1965; Julien and Fowler, 1977). In the initial study phenobarbital exhibited limited effectiveness at doses of $100 \mathrm{mg} / \mathrm{kg}$ but its protective index was less than one (Millichap, 1965). A second study found phenobarbital to significantly increase the time to onset of febrile convulsions only at a dose (400 $\mathrm{mg} / \mathrm{kg}$ ) resulting in deep sedation and loss of the righting reflex (Julien and Fowler, 1977). Thus, normal mice do not appear to provide a suitable pharmacological model of febrile seizures. Phenytoin was inactive against febrile seizures in mice (Millichap, 1965) and this is in agreement with its failure to provide prophylaxis against febrile seizures in children (Melchior et al., 1971). Although valproic acid has been reported to be effective in reducing the incidence of febrile seizures in children (Cavazzuti, 1975) it was found to be ineffective in mice (Julien and Fowler, 1977). The results with valproate in epileptic chicks agree with the previous experimental findings. 
The observations that epileptic chicks show an agedependent high seizure susceptibility in response to hyperthermia and a delay in onset of febrile seizures following treatment with phenobarbital and not with phenytoin indicate a degree of parallelism between the syndrome in the model and that observed in susceptible children. The model differs from the syndrome seen clinically in that the epileptic chicks have a preexisting EEG abnormality and spontaneous seizures occur throughout their life. In addition, the febrile seizures were not affected by valproate. Nevertheless, the present data indicate that epileptic chicks may provide a valuable model for the study of mechanisms by which hyperthermia precipitates seizures and for studies on the pharmacology of febrile seizures.

\section{Acknowledgement}

This research was supported by the Medical Research Council of Canada Grant MT-5893.

\section{References}

Cavazzuti, G.B. (1975). Prevention of febrile convulsions with dipropylacetate (Depakine). Epilepsia 16:647-648.

Crawford, R.D. (1970). Epileptiform seizures in domestic fowl. J. Hered. 61: 185188.

Crichlow, E.C. and Crawford, R.D. (1974). Epileptiform seizures in domestic fowl II. Intermittent light stimulation and the electroencephalogram. Can. J. Physiol. Pharmacol. 52: 424-429.
Davis, H.L., Johnson, D.D. and Crawford, R.D. (1978). Epileptiform seizures in domestic fowl VII. Plasma phenytoin concentrations and anticonvulsant activity. Can. J. Physiol. Pharmacol. 56: 310-315.

Faero, E., Kastrup, K.W., Lykkegaard, N.E., Melchior, J.C. and Thorn, I. (1972). Successful prophylaxis of febrile convulsions with phenobarbital. Epilepsia 13: 279-285.

Johnson, D.D., Davis, H.L., Bailey, D.G. and Crawford, R.D. (1977). Epileptiform seizures in domestic fowl VI. Plasma phenobarbital concentrations and anticonvulsant activity. Can. J. Physiol. Pharmacol. 55: 848-854.

Johnson, D.D., Davis, H.L. and Crawford. R.D. (1979). Pharmacological and biochemical studies in epileptic fowl. Fed. Proc. 38: 2417-2433.

Julien, R.M. and Fowler, G.W. (1977). A comparative study of the efficacy of newer antiepileptic drugs on experimentally-induced febrile convulsions. Neuropharmacology 16: 719-724.

Kasting, N.W., Veale, W.L., Cooper, K.E. and Lederlis, K. (1981), Vasopressin may mediate febrile convulsions. Brain Research 213, 327-333.

Lennox-Buchthal, M. (1971). Febrile and nocturnal convulsions in monozygotic twins. Epilepsia 12:147-156.

Metchior, J.C., Buchthal, F. and Lennox-Buchthal, M. (1971). The ineffectiveness of diphenylhydantoin in preventing febrile convulsions in the age of greatest risk, under three years. Epilepsia 12:55-62.

Millichap, J.G. (1959). Studies in febrile seizures I, Height of body temperature as a measure of the febrile-seizure threshold. Pediatrics 23: 76-85.

Millichap, J.G. (1965). Anticonvulsant drugs. In. Physiological Pharmacology: A comprehensive treatise. (Root W.S. and Hofman, F.G. eds.) vol. II. Part B pp. 97-174, Academic Press, New York.

Ounsted, C. (1971). Some aspects of seizure disorders. In Gairdner D.. Hull. D. (editors), Recent advances in paediatrics. London. J.A. Churchill.

Ross, E.M. (1973). Convulsive disorders in British children. Proc. R. Soc. med. 66 703-704.

Schmidt, R.P., Ward, A.A.J. and Wolfe, W.J. (1956). Failure of hyperthermia to activate experimental epileptogenic foci in monkey. J. Pediat. 48: 180-186.

Tsuboi, T. (1977). Genetic aspects of febrile convulsions. Hum. Genet. 38: 169 173.

Van den Berg, B.J. and Yerushalmy, J. (1959). Studies on convulsive disorders in young children 1 . Incidence of febrile and non-febrile convulsions by age and other factors. Pediat. Res. 3: 298-304. 